\title{
This Month in APR
}

\section{By Suk-Jae Chung, Associate Editor}

Prediction of oral bioavailability of new drug leads has always been a major challenge for pharmaceutical scientists. In fact, inadequate pharmacokinetics/bioavailability was recognized as one of the major reasons for attrition (i.e., attrition rate of up to approximately 40\%) in new drug development programs since 1990 (Kola and Landis, 2004). Such a high attrition rate is now significantly reduced partly by the common use of high throughput intestinal permeability model such as Caco-2 cell monolayers (Artursson et al., 1996) in most major pharmaceutical companies. The preparation of a fully differentiated confluent Caco-2 cell monolayer, however, generally requires a 3 weeks cell culture period with laborious cell feedings. Thus, other permeability assessment models that are much less time-consuming such as parallel artificial membrane permeability assay (PAMPA) (Gamenisch et al., 1997) and Mardin-Darby canine kidney cells (Rabito et al., 1978) are currently being used widely. Despite the fact that these new methodologies have considerable merits as experimental tools for the prediction of human intestinal permeability, they also have limitations. For example, while the time required to assess permeability of a large number of compounds is very short (i.e., a few hours including the membrane preparation), PAMPA is unable to evaluate compounds that may utilize paracellular route and uptake transporters for intestinal absorption. MDCK cells, immortalized cells from canine kidney by Madin and Darby, have been traditionally used to study carrier-mediated transport processes in renal epithelial cells. MDCK cells form a cell monolayer with a tight junction when the cells are grown on a filter membrane (e.g., Transwell ${ }^{\circledR}$ ) in a relatively short period of time (i.e., a few days), and, thus, considerable efforts have been devoted to establish an empirical relationship between the rate of permeation across MDCK cell monolayers and human oral bioavailability (e.g., Irvine et al., 1999). Unfortunately, MDCK cells are derived from dog kidneys and the level of expression of relevant uptake drug transporters, as well as their properties, may be significantly different from those in human intestinal epithelial cells. Therefore, the utility of MDCK cell line as a model for intestinal permeability screening is limited.

In this issue, Shin et al. (2010) reported a successful establishment of stably transfected MDCK cells that are functionally expressing human organic anion transporters. OATs are the major determinants on the kinetics of anionic drugs (e.g., $\beta$-lactam antibiotics, antiviral agents, anticancer drugs and anti-inflammatory drugs) across the membrane in a number of important epithelial cells. MDCK cells functionally expressing such solute carrier transporters would serve as a superior screening tool to identify potential substrates and/or inhibitors of these drug transporters. Considering the potential application of this new cell system to detect clinically relevant transportermediated drug-drug interactions, the new experimental cell system described here is likely to have academic and practical utility.

\section{REFERENCES}

Artursson, P., Palm, K., and Luthman, K., Caco-2 monolayers in experimental and theoretical predictions of drug transport. Adv. Drug Del. Rev., 22, 67-84 (1996).

Gamenisch, G., Folkers, G., and Waterbeemd, H., Comparison of passive drug transport through Caco-2 cells and artificial membranes. Int. J. Pharm., 147, $61-70$ (1997).

Irvine, J. D., Takahashi, L., Lockhart, K., Cheong, J., Tolan, J. W., Selick, H. E., and Grove, J. R., MDCK (Madin-Darby Canine Kidney) cells: A tool for membrane permeability screening. J. Pharm. Sci., 88, 28-33 (1999).

Kola, I. and Landis, J., Can the pharmaceutical industry reduce attrition rates? Nature Rev., 3, 711-715 (2004).

Rabito, C., Tchao, R., Valentich, J., and Leighton, J., Distribution and characteristics of the occluding junctions in a monolayer of a cell line (MDCK) derived from canine kidney. J. Mem. Biol., 43, 351-365 (1978)

Shin, H. J., Lee, C. H., Park, S.-J., Shin, J.-G., and Song, I.S., Establishment and characterization of MDCK cells stably expressing human organic anion transporters. Arch. Pharm. Res., 33, 709-716 (2010).

College of Pharmacy, Seoul National University, Seoul 151742, Republic of Korea (sukjae@snu.ac.kr)

See page 709-716. 